Letter to the Editor | Public Health

\section{Strange title for a flawed study}

Leslie B Rose

\author{
Submitted: 02 August 2021 \\ Approved: 07 August 2021 \\ Published: 08 August 2021
}

Address for correspondence:

Trustee, HealthWatch (charity 1003392), and clinical research scientist (retired), Salisbury, United Kingdom.

How to cite this article: Rose LB. Strange title for a flawed study. G Med Sci. 2021; 2(4): 030-031.

https://www.doi.org/10.46766/thegms.pubheal.21080204

Copyright: (c) 2021 Leslie B Rose. This is an Open Access article distributed under the Creative Commons Attribution License, which permits unrestricted use, distribution, and reproduction in any medium, provided the original work is properly cited.

\section{To the Editor:}

I was fascinated by the study by Thorp et al. on the magnetic effects of Covid-19 vaccination - or rather the lack of the same [1]. The paper's title is in no way supported by the data. A static magnetic field is a force. The investigators did not do any tests for energy, and even their tests for magnetism were seriously flawed. They did not think to try a non-ferrous or non-metallic test article, so non-magnetic adhesive factors cannot be ruled out. It is not valid to claim that "A strong magnetic field is generated in the human body that has no causal relation to previous COVID-19 vaccination". Firstly, if the field is strong then it is detectable by scientific instruments. This was not done. Secondly, the study's methods may well have been insufficiently sensitive to detect differences between groups, so a causal relation, or lack of it, cannot be inferred.

The lead author has privately encouraged me to read the paper's references. I have, and here are some comments.

Page 2, first sentence: "As two of the authors...had recently published articles..., definitively establishing the presence of an organized energy field in the body...". Two references are given [2, 3]. Both papers are historical reviews, not research, and provide no new data. They are speculative exercises in reinterpreting established science to fit the authors' beliefs. They are the only sources cited in the introduction, as rationale for the study. Self-citation seems inappropriate without some solid science.

Several references are provided to explain the emergence of vaccination conspiracy theories, which is fine. More are provided in relation to cardiac physiology - again fine. Neither has any relevance to the claimed energy fields. But then on page 4, paragraph 2, we have:

"Nor have scientists considered what happens to the electrical currents seen on ECG after they ostensibly induce ventricular contraction. Surely, they cannot simply disappear but instead, contribute to the body's energy fields".

No source is cited for this entirely speculative notion.

For the sake of brevity, I will not detail all the other references. Suffice it to say that some have only tenuous relevance at best. For example, two papers about insulin resistance are cited to support the notion of an energy field $[4,5]$, although they say nothing about it.

So, we seem to have here the conflation of two concepts, the "energy field" and "human magnetism". I do not necessarily challenge the science on electromagnetic fields associated with the human body, but this study does not add to our knowledge about those. Neither is any evidence provided for "energy fields".

There is an intriguing passage on page 4 , column 2 , paragraph 3:

"Perhaps the most curious result of our study came with the recognition that in a significant percentage of subjects, the magnets attached to the skin on both sides (north and south poles), which seemingly violates known laws of magnetic attraction and repulsion. We have no satisfying explanation for this phenomenon". 
It might have occurred to the authors to seek a plausible explanation, e.g., that magnetism was not involved.

The adhesion of objects to the skin, claimed to be related to special "magnetic powers", was shown many years ago by James Randi to be negated by talcum powder [6].

\section{Yours sincerely}

Les Rose, BSc, CBiol, FRSB, HonFICR

Trustee, HealthWatch, UK.

\section{References}

1. Thorp JA, Thorp KE, Lile EK, Viglione J. Unexpected magnetic attraction: Evidence for an organized energy field in the human body. G Med Sci. 2021; 2(4): 001- 015.https://www.doi.org/10.46766/ thegms.pubheal.21071202
2. Thorp KE. Morphogenic fields: A coming of age. Explore 2021 Apr.7:S1550- 8307(21)00078-1.

3. Thorp KE, Thorp JA. Ozone Preconditioning: Waking up the dragon. G Med Sci. 2021; 2(3): 010-039. https://www.doi.org/10.46766/thegms. intmed.21051402

4. Reaven GM. Banting lecture 1988. Role of insulin resistance in human disease. Diabetes.

5. Reaven GM. Role of insulin resistance in human disease (syndrome X): An expanded definition. Annu Rev Med. 1993;44:121-31

6. https://www.youtube.com/watch? $\mathrm{v}=\mathrm{OTVWMY8}$ EZCA\&list=WL\&index $=19$ (accessed 2nd August 2021) 